\title{
An integrative review of computational methods for vocational curriculum, apprenticeship, labor market, and enrollment problems
}

\author{
Ahmad Dardiri ${ }^{a, 1, *}$, Felix Andika Dwiyanto ${ }^{a, 2}$, Agung Bella Putra Utama ${ }^{a, 3}$ \\ ${ }^{a}$ Faculty of Engineering, Universitas Negeri Malang, Malang, Indonesia \\ 1 ahmad.dardiri.ft@um.ac.id; ${ }^{2}$ felix.adwiyanto@gmail.com; ${ }^{3}$ agungbpu02@gmail.com \\ * corresponding author
}

\section{ARTICLE INFO}

\section{Article history}

Received October 29, 2020

Revised November 12, 2020

Accepted November 12, 2020

Available online November 13, 2020

\section{Keywords}

Computational method

Vocational curriculum

Apprenticeship

Labor market

Enrollment

\section{ABSTRACT}

Computational methods have been used extensively to solve problems in the education sector. This paper aims to explore the computational method's recent implementation in solving global Vocational education and training (VET) problems. The study used a systematic literature review to answer specific research questions by identifying, assessing, and interpreting all available research shreds of evidence. The result shows that researchers use the computational method to predict various cases in VET. The most popular methods are ANN and Naïve Bayes. It has significant potential to develop because VET has a very complex problem of (a) curriculum, (b) apprenticeship, (c) matching labor market, and (d) attracting enrollment. In the future, academics may have broad overviews of the use of the computational method in VET. A computer scientist may use this study to find more efficient and intelligent solutions for VET issues.

This is an open access article under the CC-BY-SA license.

\section{Introduction}

Vocational education and training (VET) are aspects of the general educational process, including research on technology and related sciences and practical skills, attitudes, understanding, and knowledge acquisition [1]. In other words, VET is an education that aims to prepare high-skilled prospective workers as a provision to develop a career in life. Therefore, the VET curriculum must always be adjusted to the development needs of the industry. It must be able to adapt to rapid and even destructive industrial development. In this 4.0 era, technological progress development encourages vocational education and training to meet industrial capabilities' needs. However, its graduates also can adapt to the changes that have occurred [2]. VET must cultivate students' attitudes, knowledge, skills, and values to make them productive people. The success of VET depends on students' academic performance in school and the workplace.

The various Organisation for Economic Co-operation and Development (OECD) countries, which have succeeded in revitalizing VET, show that VET's main characteristic is the industry and the government's strong support. Also, the systems in OECD countries show evidence that (1) strong industry support to provide students with experience in apprenticeship, (2) the government must facilitate and ensure that the industry plays an active role in the VET implementation, (3) intense research between industry and VET institutions [3]. Therefore, concrete cooperation between schools and industry is needed to achieve quality graduates [4][5]. The government has also followed up on 
industrial cooperation's importance through various policies such as revitalizing vocational education, industrial apprenticeship teachers, revitalizing student competence through internships.

However, there are several problems related to the VET environment. For example, in South Asia, the problem is a lack of adequate practical training as a part of VET and the insufficient connection between higher and lower VET institutions [6][7]. Although this was a problem in East Asia's early development, this weakness has been resolved, even in Vietnam. For example, in Vietnam, the main difference between secondary professional schools and vocational secondary schools is that the proportions of theory and practice in each school are different. Technical secondary school courses are about $40 \%$ of practical courses and $60 \%$ of theoretical courses. Simultaneously, secondary vocational schools' courses account for about $70 \%$ of practical courses and $30 \%$ of theoretical courses [8]. Besides, technical secondary school graduates are eligible to enter universities. However, as in South Asia, graduates of secondary vocational schools cannot enter technical colleges, and graduates of vocational colleges cannot enter universities. Fortunately, Vietnam has recently corrected this situation. In these two types of institutions, the ratio of theory to practice has become more standardized, and graduates of vocational colleges can now enter universities [8].

These problems can be solved computationally. The computational method has proven successful in solving educational problems. For example, in higher education, this method is used to predict student graduation [9], for student admission selection [10] and predict student failure and dropout [11]. Secondary school is used to solve students' academic predictions [12], predict student performance [13], and predict students' final grades [14]. Meanwhile, the primary school is used for comprehensive classification between teachers and students [15], predicting student performance [16], and for assessing students about the quality of teaching [17]. Of the many studies, the VET field has not been discussed much, so that it is still possible to develop.

VET is a special education that is important to be developed, especially in developing countries. However, VET has several problems in its implementation, including curriculum and technical implementation, to educational products. So far, many studies have focused on finding solutions to problems in VET, including the use of a computational method to offer a solution to the VET problem. For example, a genetic algorithm (GA) [18] is used for VET students' career guidance. Also, an artificial neural network is used for prediction and classification [19]-[22]. Therefore, this paper focuses on the implementation of computational methods in solving VET problems. The next section will describe the method and design of this study.

\section{Method}

Systematic literature review (SLR) aims to answer precise research questions through the process of identifying, assessing, and interpreting all available research shreds of evidence [23] [24]. A clearly defined protocol or strategy should be followed for a systematic review of the requirements before the review is performed. It is a systematic, transparent search that other researchers can repeat and reproduce over numerous databases and grey literature. It involves preparing a well-thought-out search method that has a particular emphasis or answers a given question. Under known timeframes, the analysis defines the type of information searched, criticized, and published. Search words, search methods (including the names of the sites, platforms, search dates), and restrictions must all be included in the analysis. Fig. 1 shows the steps of SLR [8].

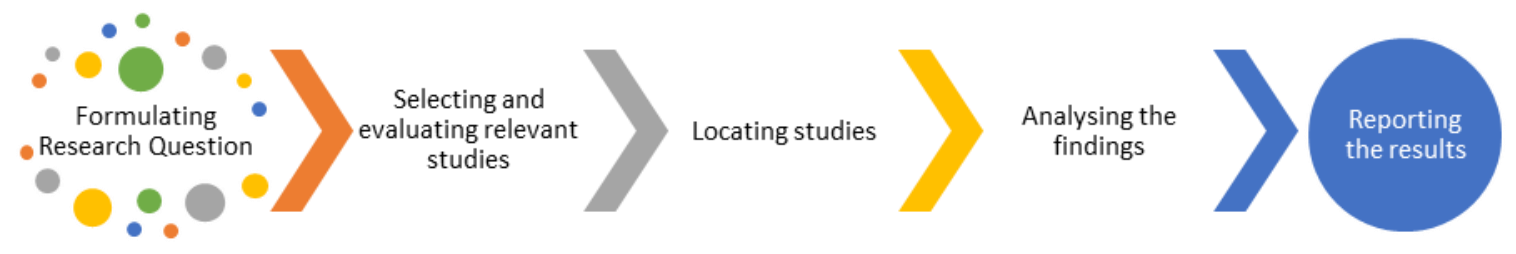

Fig. 1.Scientific literature review (SLR) process 


\subsection{Formulating research question}

Before beginning any study, the formulating research question is an essential element. It attempts to examine current ambiguity in a field of concern and points to the need for an intentional investigation. The formulation of the research question has the purpose of keeping the review on track. The question must be in PICOC criteria: population, intervention, comparison, outcomes, and context [18]. Table 1 shows the structure of the research question based on PICOC. Table 2 shows the research question and motivation derived from Table 1.

Table 1. PICOC Structure of Research Questions design based on PICOC

\begin{tabular}{ccccc}
\hline Population & Intervention & Comparison & Outcomes & Context \\
\hline $\begin{array}{c}\text { A vocational, vocational } \\
\text { school, vocational high } \\
\text { school, Vocational } \\
\text { teacher, vocational }\end{array}$ & $\begin{array}{c}\text { Vocational prediction, } \\
\text { association, clustering, } \\
\text { student, vocational } \\
\text { education }\end{array}$ & $\begin{array}{c}\text { Comparison } \\
\text { methods, techniques, }\end{array}$ & Accuracy of & Studies in \\
methods & & $\begin{array}{c}\text { computational } \\
\text { methods in the } \\
\text { vocational education } \\
\text { environment. }\end{array}$ & $\begin{array}{c}\text { vocational education } \\
\text { approach in }\end{array}$ \\
\hline
\end{tabular}

Table 2. Research Questions On Literature Review

\begin{tabular}{ccc}
\hline Id & Research Questions & Motivation \\
\hline RQ1 & $\begin{array}{c}\text { What types of research topics do } \\
\text { researchers in the field of vocational } \\
\text { education? }\end{array}$ & $\begin{array}{c}\text { Identify research topics and trends in } \\
\text { vocational education }\end{array}$ \\
RQ2 & $\begin{array}{c}\text { What types of data sets are most used for } \\
\text { computation in the field of vocational } \\
\text { education? }\end{array}$ & $\begin{array}{c}\text { Identify data sets commonly used in } \\
\text { computation in the field of vocational } \\
\text { education }\end{array}$ \\
RQ3 & $\begin{array}{c}\text { What types of methods are used for } \\
\text { computation in the field of vocational } \\
\text { education? }\end{array}$ & $\begin{array}{c}\text { Identify opportunities and trends for } \\
\text { computation in the field of vocational }\end{array}$ \\
RQ4 & $\begin{array}{c}\text { What types of methods are most often } \\
\text { used for computation in the field of } \\
\text { vocational education? }\end{array}$ & $\begin{array}{c}\text { Identify the most frequently used methods } \\
\text { for computation in the field of vocational } \\
\text { education }\end{array}$ \\
RQ5 & $\begin{array}{c}\text { Which method performs best when used } \\
\text { computation in the field of vocational } \\
\text { education? }\end{array}$ & $\begin{array}{c}\text { Identify the best computation method in } \\
\text { the field of vocational education }\end{array}$ \\
\hline RQ6 & $\begin{array}{c}\text { What types of improvement methods are } \\
\text { proposed for s computation in the field } \\
\text { of vocational education? }\end{array}$ & $\begin{array}{c}\text { Identification of improvements to the } \\
\text { proposed method for computation in the } \\
\text { field of vocational education }\end{array}$ \\
\hline
\end{tabular}

\subsection{Selecting and evaluating relevant studies}

The second process chooses and assesses appropriate research based on parameters of inclusion and exclusion. Selecting a source to use in an assignment requires careful evaluation. It is crucial to select the information that comes from a reputable source. Table 3 lists the parameters that we research from journal articles. However, this analysis does not involve literature review records.

Table 3. Inclusion and Exclusion Criteria

\begin{tabular}{cc}
\hline Inclusion Criteria & Exclusion Criteria \\
\hline $\begin{array}{c}\text { Studies in the use of the computational method } \\
\text { in vocational education use large and small scale } \\
\text { data sets. }\end{array}$ & Studies without experimental results. \\
$\begin{array}{c}\text { Studies that discuss and compare modeling } \\
\text { performance in the area of the computational } \\
\text { method in vocational engineering. }\end{array}$ & $\begin{array}{c}\text { Computational studies outside the vocational } \\
\text { education }\end{array}$ \\
Conference or journal papers from 2010-2020. & Non-English written studies \\
\hline
\end{tabular}

Dardiri et al. (An integrative review of computational methods for vocational curriculum, apprenticeship, ...) 


\subsection{Locating studies}

One of the most effective ways to locate high-quality literature review resources is to use the library's subject-specific database. Begin to search the library databases for current articles and other materials related to the research. A library database such as an e-journal is a searchable electronic index of periodicals and other materials. E-journal makes it easy to find scholarly articles or to find articles written within a specific period.

As in Fig. 2, the third stage consists of searching for papers in many digital databases. The search is based on Table 1 keywords. Synonyms, alternate orthography, and antonyms for search words are also listed. For refined search results, we have used boolean (AND and OR).

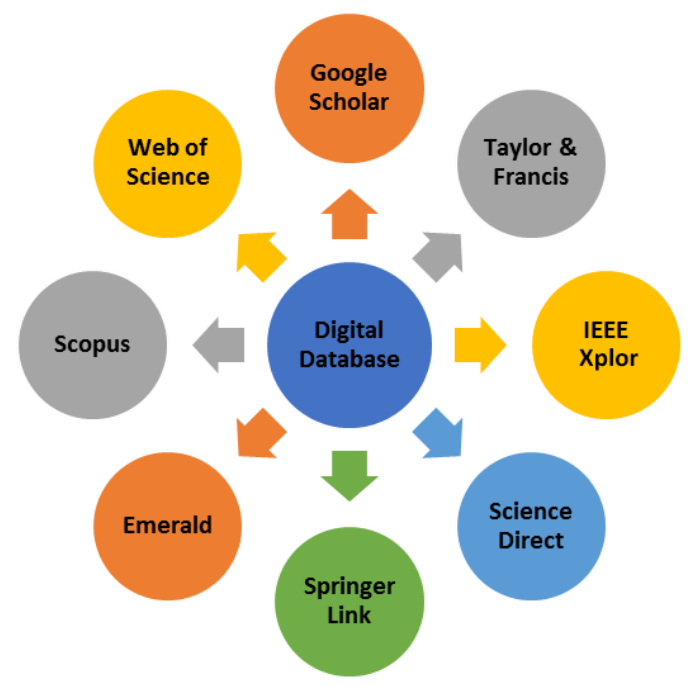

Fig. 2. Searched databases

\subsection{Analyzing the findings}

It is a process of managing some of the data. After collecting document evidence or collecting material from books, and so on, the next step is to develop an analysis for the process to become information. In this study, we compare published studies to find out the results of analyzing the findings.

\subsection{Reporting the result}

The last steps are the interpretation of the findings. After collecting and analyzing data, it is time to develop recommendations and share the evaluation's findings. The study aims to address questions from the report. In order to provide clear guidance to potential outcomes, a structural report should be made.

\section{Results and Discussion}

This section will describe global issues on VET and the assistance of computational methods to overcome it. There are many computational methods used in VET, such as genetic algorithm, Bayesian network, artificial neural network, and so on. Also, from many issues that we found, we classify it into four categories which are (a) curriculum, (b) apprenticeship, (c) matching labor market, (d) and attracting enrollment.

\subsection{Computational methods in VET}

We found 31 of 128 articles related to the application of the computational method in vocational education. Table 4 shows 13 approaches and their application. Some approaches, such as ANN, C.45, Naïve Bayes, and Bayesian Network, have several roles. The existing computational methods can be used in various fields such as expert systems, prediction, decision support systems, clustering, and classification. 
Table 4. Computational methods in VET

\begin{tabular}{|c|c|c|c|c|c|c|}
\hline \multirow[b]{2}{*}{ Method } & \multicolumn{5}{|c|}{ Roles } & \multirow[b]{2}{*}{$\begin{array}{l}\text { Number of } \\
\text { Paper }\end{array}$} \\
\hline & $\begin{array}{l}\text { Expert } \\
\text { System }\end{array}$ & Prediction & $\begin{array}{c}\text { Decision } \\
\text { Support } \\
\text { System }\end{array}$ & Clustering & Classification & \\
\hline Genethic Algorithm [18] & $\sqrt{ }$ & & & & & 1 \\
\hline Bayesian Network [25] & $\sqrt{ }$ & & & & & 1 \\
\hline $\begin{array}{l}\text { Artificial Neural Network } \\
{[19][26][27][20][28][21][22]}\end{array}$ & & $\sqrt{ }$ & & & $\sqrt{ }$ & 7 \\
\hline Decision Tree C4.5 [29][30] & & $\sqrt{ }$ & & & $\sqrt{ }$ & 2 \\
\hline K-Nearest Neighbor [31] & & $\sqrt{ }$ & & & & 1 \\
\hline $\begin{array}{c}\text { Linier Regression } \\
{[32][33][34][35][36]}\end{array}$ & & $\sqrt{ }$ & $\sqrt{ }$ & & $\sqrt{ }$ & 5 \\
\hline $\begin{array}{l}\text { Linier Support Vector } \\
\text { Machine }[37]\end{array}$ & & $\sqrt{ }$ & & & & 1 \\
\hline Promothee Method [38] & & & $\sqrt{ }$ & & & 1 \\
\hline Fuzzy Logic [39] & & & $\sqrt{ }$ & & & 1 \\
\hline $\begin{array}{c}\text { Naïve Bayes } \\
{[40][41][42][43][44][45][46]}\end{array}$ & & $\sqrt{ }$ & $\sqrt{ }$ & & $\sqrt{ }$ & 7 \\
\hline Ripper [47] & & & & & $\sqrt{ }$ & 1 \\
\hline Grey Model [48] & & $\sqrt{ }$ & & & & 1 \\
\hline $\begin{array}{c}\text { K-Means Clustering } \\
{[49][50]}\end{array}$ & & & & $\sqrt{ }$ & & 2 \\
\hline
\end{tabular}

The distribution of Vocational education and training that have used computational methods in the world's learning process has spread in various countries. As shown in Fig. 3, it can be seen that the country that uses the most computational methods in Indonesia, which has 16 research papers, followed by Turkey (6). Meanwhile, for other countries such as Malaysia, Austria, and France, the rest still have 1 published paper regarding the use of VET computation methods.

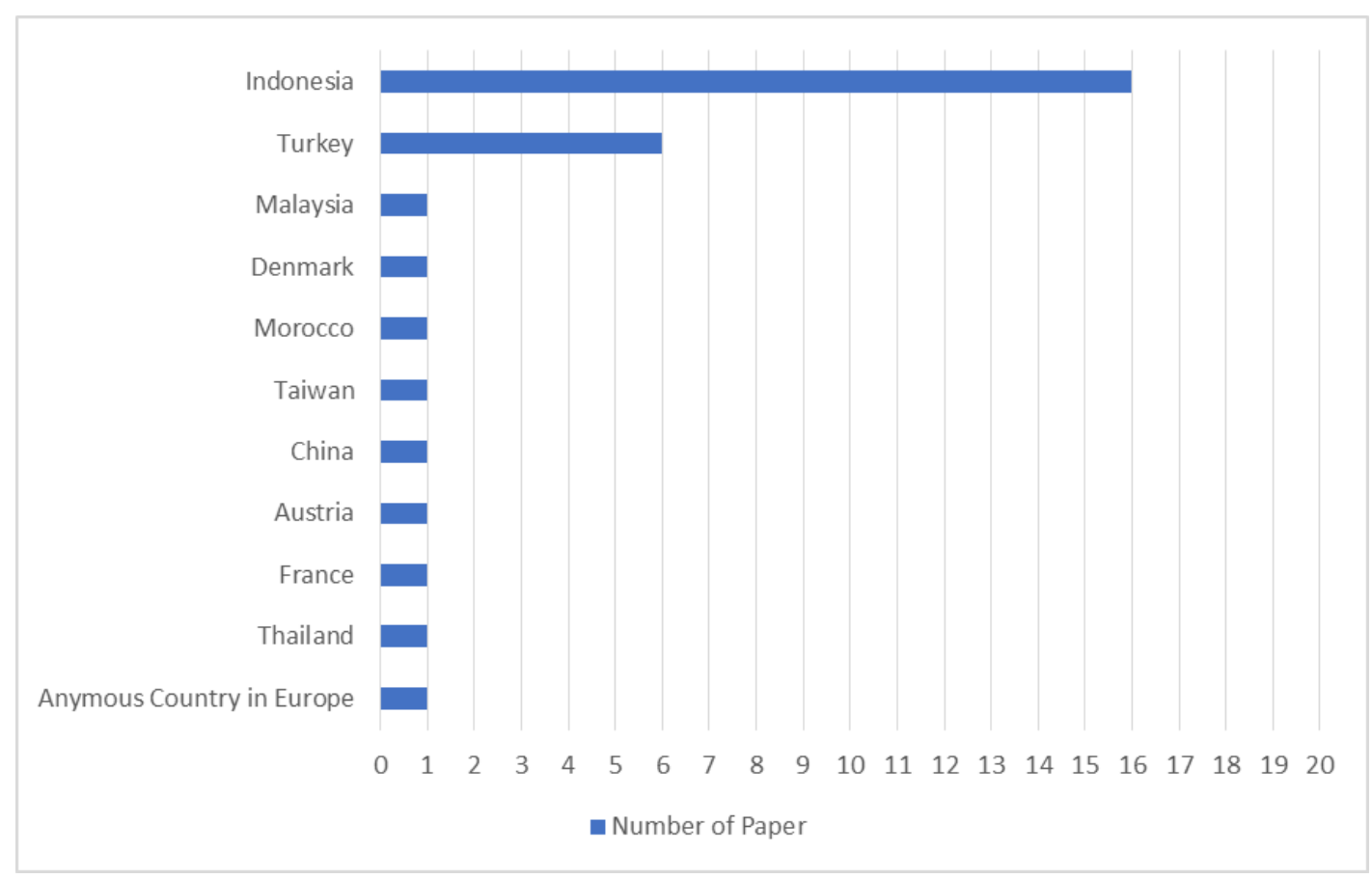

Fig. 3. Paper demography 


\subsubsection{Genetic algorithm}

A genetic algorithm (GA) is a metaheuristic that belongs to the broader class of evolutionary algorithms (EA), inspired by the mechanism of natural selection. In VET, GA is used for students' career guidance [18]. Education and career advice are the issues discussed in this article, in which various professional knowledge comes from four aspects: teaching experts, psychologists, sociology experts, and economic experts. In addition to the four experts listed, the other two experts also added a coaching expert and system supervisor

To optimize the combination of an acquired profile and a career profile, GA is used. This pairing is based on many $\mathrm{Ci}$ parameters related to weights (coefficients). We tend to simplify for these different parameters: the weights mentioned below are 0 not important, 1 is important, and 2 is very important. Second, according to various parameters $\mathrm{Ci}$, we must continue to classify transactions. Therefore, the use of genetic algorithms to optimize multi-criteria problems requires evaluating the results of individual multi-criteria analysis. In the future, GA can be used to arrange the topic of VET.

\subsubsection{Bayesian network}

Bayesian network (also known as Bayesian network, belief network, or decision network) is a probabilistic graphical model that expresses a set of variables and their conditional correlations through a directed acyclic graph (DAG). In VET, Bayesian network is used for the design of expert system for education career guidance [25]. As far as the research design is concerned, Bayesian networks are used to determine the most "probable" path. In fact, like other places in Morocco, many ways may be different, such as length, cost, and quality, such as becoming a computer engineer. The network they are analyzing is an example of various ways to become a computer engineer in Morocco.

In future work, Bayesian networks will be able to focus on use in order to compare results and select the best results, and at the same time, use the results obtained to implement instructive social networks to achieve connection and coordination between different actors: students and their parents, job seekers, teachers, consultants, pro-leaders.

\subsubsection{Artificial neural network}

An ANN is based on artificial neurons called linked units or nodes that loosely model the neurons in the biological brain. In VET, ANN is used for prediction and classification. The example of ANN prediction is used for is various, such as academic achievements [19] [22], programming talent [26], selection of majors [27], scores prediction [20], and LMS acceptance [28]. On classification ANN used for vocational competence selection [21].

In a study on academic achievement, it is assumed that the attribute that affects academic achievement is regarded as the independent variable/input, and the dependent variable/output is regarded as the average academic achievement year of students in the previous physics, chemistry and biology courses. A model was developed using these parameters, and the academic achievement of students with artificial neural networks is expected. At the end of the study, a useful learning performance prediction framework was established, with an average sensitivity of $98.0 \%$ for 922 samples from Turkey and $95.7 \%$ for 1050 samples from Malaysia, and measures to avoid student failure were determined.

In future work, different ANN studies on VET issues may be conducted. According to different cultural and demographic backgrounds, the participants' survey questions can be further diversified and personalized. One example is that the recommendation framework for artificial neural networks will help students choose future jobs to attract more student samples and focus on older age than vocational education and training, such as middle school students. The recommendation framework is an effective government-sponsored service, hoping to generate encouraged demand for graduates, and it needs to be more integrated into the VET.

\subsubsection{Decision tree C4.5}

A decision tree is the most used classifier for predictive modeling. In VET, C4.5 is used for classification and prediction. In classification, the implementation is used for the analysis of scholarship awardees [29]. The provision of scholarship recipients who were not on track, exacerbated by the uneven 
distribution of information and inappropriate decision-making, was one of the barriers to its implementation. It is vital to examine the data on past recipients of the scholarship to solve this problem. The implementation of the algorithm is achieved by the entropy of measurement and knowledge acquisition value. Later, to construct the decision tree nodes, the entropy data gain values obtained are used. Entropy (total) is obtained by counting 1011 cases where 682 points are "accepted" and 329 are "rejected" by classification. Then, each attribute value's entropy value is determined. The test findings using the Uncertainty matrix and the validation results using cross-validation indicate an accuracy rate of $78.54 \%$ with $79.18 \%$ accuracy and a recall rate of $92.67 \%$.

In predicting VET students' career suitability [30], some graduates are suitable for vocational school majors, but many graduates are not suitable for their majors. The test is conducted in all student data training, and the confusion matrix is composed of a data set processed using algorithm C4.5, including accuracy, accuracy, and recall. In Algorithm C4.5, each attribute's consistency did not show a tendency to a value between 0 and 1 , and an accuracy value of $89.14 \%$ was obtained. It is expected that the use of C4.5 will help predict the number of graduates of VET students so that they can play a role according to the school's vision and purpose and accurately according to the field occupied by the school.

\subsubsection{K-nearest neighbor}

K-Nearest Neighbor (KNN) is one of the Lazy learning techniques. The k-nearest neighbor algorithm is a classification algorithm based on the proximity of data to other data. In VET, KNN is used for the prediction of student behavior [31]. Some of the data that will be processed include attendance, issue lateness notices, instructor responses, tuition payment, and broken houses. Data from 100 vocational students from different classes and different majors and divided into two groups was the sample being studied. It can be shown from this experiment that the value of $K=1,3$ and 4 is the most reliable $\mathrm{K}$ value. The accuracy of the produced test data is $94.9 \%$. The accuracy rate is higher at a smaller $\mathrm{K}$ value, and the accuracy is decreased at a larger $\mathrm{k}$ value.

There was an issue with that experiment when the data was taken from student data, requiring further test data and its degree of accuracy. The test function is also an aid to its degree of precision. The more features, the better it will be, but the amount of data checked must also be high; otherwise, overfitting will occur. So students need to be big enough to test the test data for schools with several features consistently. In the future, by using the same amount of attributes to generate accurate information, K-Means can be used to predict the habit habits of junior high school students from different regions of the world, such as Asia, Europe, Australia, America, and Africa.

\subsubsection{Linear regression}

Linear regression is a linear approach to modeling the relationship between a dependent variable and one or more independent variables. In VET, linear regression is used for prediction, classification, and decision support systems. In prediction use for student's psychomotor domain [33] [36] and potential dropout students [32], in classification roles use for developing vocational research [35] and in decision support system used for potential dropouts [34].

Depending on the magnitude, frequency, and type of factors involved, absenteeism reduction programs may be structured at different levels [36]. Their research is in line with these guidelines because, on the one hand, it shows that in order to adapt preventive programs better, it is essential to investigate various forms of absenteeism in vocational secondary school and, on the other hand, beyond the influence of personal variables, the organization of the educational system seems to be a significant predictor in explaining different degrees.

Implications for practice are recommended to take into account the characteristics of the varying degrees of absenteeism and the specificity of the school's background to motivate VET students to attend school. In order to determine the professionalism of vocational teachers in teaching, linear regression for further study in VHS can be used to determine the professionalism of vocational teachers in teaching, a factor that influences the motivation of vocational students to pursue their studies in higher education, and the efficacy of vocational learning in VET according to their respective fields of talent. 


\subsubsection{Linear support vector machine}

Linear Support Vector Machine (LSVM) has become popular in solving prediction tasks because it can be quickly and easily applied to large-scale data sets online. In VET, LSVM is used for real-time prediction of national identity [35]. This section presents the results of predicting the ethnic identity of European academic school students. Dataset1 has 49,263 instances with 130 features and uses 10-fold cross-validation to train them to predict students' ethnic identity. Of the 145 features obtained by SVM through its result analysis, the country's largest accurate number is estimated to be 33,737 . Sadly, it failed to estimate a huge number of immigration. Future work LSVM will use all VET worldwide to build a real-time website to define, track, and regulate the different ICT parameters that could be useful.

\subsubsection{Promothee method}

The Promothee method is a multi-standard decision support framework that allows overlap between various alternatives. In VET, the promotee method is used in the decision-making system of school elections [38]. This research aims to provide knowledge and alternative methods in rankings to solve the VET selection problem so that parents and the community can choose the best school for their children's comments. Promethee (Promethee) is a method used to make recommendations for choosing a location for vocational high school education. Location, equipment, number of achievements, school atmosphere, and extracurricular activities are the parameters for choosing the location of high school vocational education.

Promethee has specific decision-making applications and is used worldwide in a wide variety of decision contexts in areas such as manufacturing, government departments, transport, healthcare, and education include VET. Prmothee should process the ranking of VET school status in Southeast Asia for potential study since countries in Southeast Asia have joined the MEA (Masyarakat Ekonomi Asia) that can open up opportunities for VET students to exchange students and intern abroad for industrial internships.

\subsubsection{Fuzzy logic}

It clarifies that fuzzy logic, as one of the software components, has been widely used in various life fields. In VET, fuzzy logic is used in the main selection decision support system [39]. The decisionmaking process of selecting students with a VET major is one of the functions of the Educational Decision Support System (DSS), which can help decision-makers provide options that can be used to assist teachers in making decisions. The three variables of IPA, B.ING, and TIK scores can be used to evaluate the department. In VET DSS, the fuzzy logic model uses the degree of membership of the value and then uses the determined rules to determine the desired result's operation.

One of the most critical uses is to support people in the decision-making process. When more and more situations involve decisions that can only be answered with "yes" or "no", it is essential to apply fuzzy logic to decision support. This method is the product of uncertainty about future industry honors, scholarships, and internships chosen by vocational education and training.

\subsubsection{Naïve bayes}

The main characteristic of the method is a firm assumption of each condition or event's independence. It is assumed that each attribute is mutually independent of each other based on the class attribute. Naïve Bayes in VET used for many implementations, such as prediction, classification, and decision support systems. In classification use for department recommendations [42][41] and for internship placement recommendation [44] also used for developing thinking skills on decision support system [46].

The implementation of this method is used for student eligibility [43] and to predict student learning achievement [45][40]. In Indonesia, VET graduates need to have enough incentive to get into the working world either as staff or as entrepreneurs. In vocational education, monitoring the motivation and achievement of students is significant. It will help clarify the students' situations and provide a summary of the best curriculum for the students. One of the types of education in Indonesia is vocational 
training. To get into the working world, VET graduates need to have enough incentives, either as workers or as entrepreneurs. Monitoring of students' motivation and achievement is critical in vocational education. It will explain the students' circumstances and provide the students with a review of the right curriculum.

Future research on VET use Naïve Bayes can be implemented in the apprenticeship issue, because only slightly research that studied about that. In contrast, apprenticeship is one of VET's main characteristics. A recommendation for further research is by conducting research on topics which is still a few researched, such as attracting students' enrollment. The exploration of naïve bayes for the best method by combining other approaches also can be an option for future research.

\subsubsection{Ripper}

A learning algorithm used in creating data classification laws is Repeated Incremental Pruning to Produce Error Reduction (RIPPER). One of the most effective and used algorithms for rule learning is RIPPER. To control induction, it applies a divide-and-conquer strategy. Ripper in VET is used for classifying bad student behaviors [47]. The researchers aimed to classify and define the variables that influenced the bad behaviors in this experiment and would also like to describe each group. The RIPPER classification would have an accuracy value of $80.11 \%$ and reduce the number of attributes to 11 .

The researcher may study the appropriate problem in school for future work of the ripper method on VET, including other solving and other items to improve precision and accuracy in data classification, such as solving VET students' bad behavior to get more students who have good behavior.

\subsubsection{Grey model}

Grey model's usage predicts the change of the system after examining the combination of precise data and variable information. It means that Grey is used to forecasting the time-dependent gradation process of changing in a specific area or range. In the VET, the grey model method is used to forecasting strategies and analyze incoming students [48]. A strict policy in Taiwan has been transparently observed in recent years that governments often appear to concentrate on vocational and technical education, which is believed to produce meaningful and miraculous improvements in their economy. However, this pattern faces many challenges: excellent courses and support services, long-term productivity in training staff, are becoming obsolete; students are less interested in vocational schools; educational restructuring and funding goals are also unclear.

Consequently, in terms of how these numbers will increase or decrease soon, the researcher wants statistical data. As a result, when the downturns go to the "hot" majors, the pattern experiences a massive rise in home economics at the same time. To be more precise a steady and minor decrease is noted. Therefore, the gray model will give the Ministry of Education a holistic vision for each country to take future realistic action on VET education policies and resource allocation.

\subsubsection{K-Means clustering}

$\mathrm{K}$-means clustering originally started from signal processing. It is a form of vector quantization designed to divide observations into $\mathrm{k}$ clusters, where each observation belongs to the one with the most mean value (cluster center or cluster centroid) Cluster, as the prototype of the cluster. K-means clustering in VET is used for student academic failure analysis [49] and school promotion strategy [50]. This results in the data space being partitioned into Voronoi cells. It's common in data mining for cluster analysis.

For students' academic failure analysis and research, the collected data are divided into three categories. Investigate each cluster to determine the factors that play a role in student failure and their relationship. Make sure that the first batch of students cannot answer multiple questions on the same day. The students pointed out in the second group that some topics are important to them. The students encountered some problems in this cluster that they could not share with others. In general, the group of students who have school problems is the students in the third group. Finally, the application survey results are presented, which considers work aimed at reducing the causes of failure. 
For the school promotion strategy, the student groups are divided into five groups: the first group comprises 22 students, the second group is composed of 10 students, the third group is composed of 10 students, and the fourth group is composed of 33 students. The fifth group is composed of 25 students. This pattern of results aims to promote large-scale data mining to promote the strategic promotion of new potential learners. It is hoped that in the future, the VET cluster will be used to combine skills in the VET field with courses used to make the activities of a technology-based education system simpler and faster.

\subsection{Global issues on VET}

The previous sub-section discusses the utilization of computational methods to solve global issues on VET. From various issues, it can be classified into four categories which are (a) curriculum, (b) apprenticeship, (c) matching labor market, and (d) attracting enrollment. Fig. 4 illustrates the global issue on VET and the possible solution using the computational method.

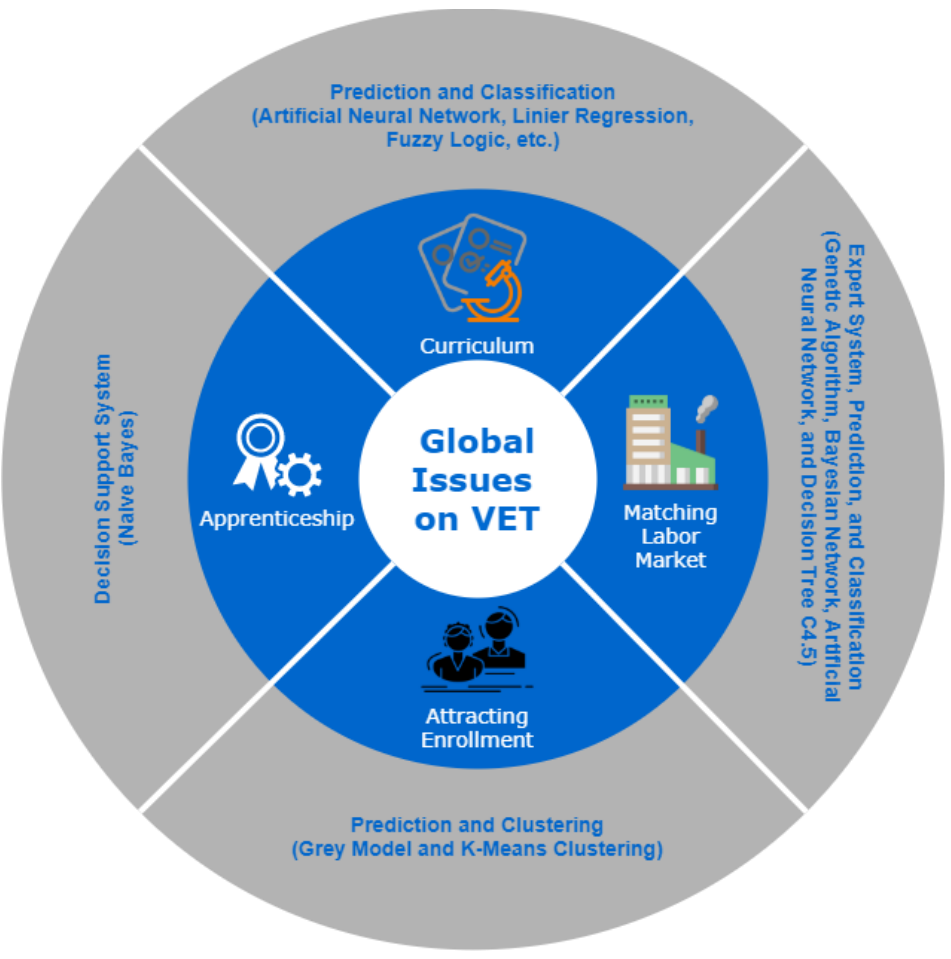

Fig. 4. Global Issues on VET and its Solution using Computational Method

\subsubsection{Curriculum}

Usually, VET follows a standardized curriculum that incorporates general and occupational-specific expertise. Compulsory schooling incorporates VET as an alternative to academically focused schooling or a variety of post-compulsory education choices. Government, employers, social partners, educational institutions, and all stakeholders need to be involved in curricula growth, with a specific assignment of responsibilities to ensure curricula relevance. The weight of the respective voices can vary from country to country. Inadequately sensitive programs to the industry's demand should be evaluated by involving the industry.

Disruptive technology transition would affect the quantitative and qualitative demands of labor markets worldwide [4]. The exponential speed of transformation on a global scale is a unique challenge. The VET must then strive to evolve, adapt, turn, and create. Also, related problems such as inclusion, equity, and greening still need to be discussed in VET programs' transformational frameworks. The transformation of VET systems is a constant and endless process.

Based on the previous debate, a computational approach has several issues with the VET program that could be overcome. About seven computational methods have been applied, such as artificial neural network, decision tree c.45, K-Nearest Neighbour, Linear regression, fuzzy logic, naïve bayes, and ripper. 
For example, an artificial neural network and fuzzy logic can predict the majors that are suitable for students [27], [51]. In linear regression, classification is used for developing vocational education research [35]. In naïve bayes, it can be used to predict students' learning achievement [40], [45]. Both methods may be used as an optional solution or merely as a guide for designing a better VET program.

\subsubsection{Apprenticeships}

Apprenticeship refers to a method in which a learner acquires business learning expertise and works side-by-side with professionals in-classroom training. In certain countries (the United Kingdom, the United States, and Australia), standardized apprenticeships offer VET, with institutional guidance complementing workplace-based teaching.

In Austria, Denmark, Germany, and Switzerland, the dual VET is between $40 \%$ (Austria) and $80 \%$ (Switzerland) of all school leavers. The following four main institutional components are shared by the dual apprenticeship programs of these four nations. Firstly, a high degree of formalization. Offer instruction in centrally approved vocational skills and continually change the training content to suit the evolving needs of the job market. Second, good participation of the social partners. The representative advisory boards' aid with the creation and maintenance of curricula at the government and federal levels. Regional Trade or Occupational Commissions, or a mixture of them, shall conduct implementation and supervision. Third, technical colleges have a school-based component of dual apprenticeships. Colleges cover both general and vocational schooling. The government pays the burden of school tuition. Fourth, companies shall conform with such technical requirements. A teaching company will not be awarded accreditation if the requirements are not met.

Based on the findings, naïve bayes used for internship or apprenticeship placement recommendation [44]. For further research, a prediction of required skills and the ability to enter the industry demands could be designed. The system may aid the students in preparing those industrial requirements.

\subsubsection{Matching labor market}

The more flexible labor market, rapid changes in technology and work organization, and the need to make more attractive and flexible VET are becoming significantly important [52]. VET can reduce unemployment through pre-vocational specialization. However, more complex problems are mismatches between graduates' skills and the labor market [53].

The computational method overcome matching labor market problems. For example, a genetic algorithm and Bayesian network are used for students' career guidance [18]. A decision tree also can be used to predict the students' careers [30]. It is useful for both students and the industry. The developed system can guide students to select the most suitable workplace. On the other hand, the industry can select the best worker candidate.

In the future, the association approach can be used in matching labor issues. Rules between graduates and labor markets can be found using apriori techniques [54] and generalized rule induction [55].

\subsubsection{Attracting enrollment}

VET is less popular than general secondary schools. More than $70 \%$ of students enrolled in secondary education, while in some counties, VET students are less than $1 \%$ of the students' population [53]. Attracting enrollment is necessary to gain as much as possible students in VET.

A grey model is used to forecast strategies and analyze the numbers of incoming students [48]. The school uses the prediction to select the best option to perform students' enrollment. On the other hand, a $\mathrm{K}-$ Means Clustering is used in the school promotion strategy [50]. It is expected to support strategic promotion in gaining new prospective students. For further research, those clustering techniques could be used to map the potentials students living area. The candidates may prioritize enrolling in the most favorite VET school nearest to their locations by this mapping. 


\section{Conclusion}

VET has several problems, including curriculum, apprenticeship, matching the labor market, and attracting enrollment. This paper uses a systematic review technique to discover computational methods to solve those VET problems. Some computational approaches, such as Naïve Bayes, ANN, and, C4.5 are useful for prediction cases. Deep learning may have a significant role in solving VET problems in a well-organized way. However, it is still not practical for solving the apprenticeship problem. Future research may design a hybrid forecasting method to predict the skills needed to meet industry needs. The system can help students prepare for those industrial requirements.

\section{Acknowledgment}

The success of this analysis depends on numerous colleagues. We could not accomplish our research goals in this analysis without them. We thank the engineering faculty for the use of the conference room, internet, and other services. Finally, researchers wish to thank those who endorse innovations and resources.

\section{Declarations}

Author contribution. All authors equally endorsed this paper. The first author directs the team and establishes the research and processes. Evidence of VET computations is obtained from the second and third authors. All contributors read, accepted, and wrote the final document.

Funding statement. None of the authors have received any funding or grants from any institution or funding body for the research.

Conflict of interest. The authors declare no conflict of interest.

Additional information. No additional information is available for this paper.

\section{References}

[1] J. S. Tripney and J. G. Hombrados, "Technical and vocational education and training (TVET) for young people in low- and middle-income countries: a systematic review and meta-analysis," Empir. Res. Vocat. Educ. Train., vol. 5, no. 3, Dec. 2013, doi: 10.1186/1877-6345-5-3.

[2] A. Wolf, "Review of vocational education," London, 2011, Available at: Google Scholar

[3] Y. Po, "Understanding Vocational Education Market in China," No. 6, 2014, Available at: Google Scholar

[4] T. Schröder, "A regional approach for the development of TVET systems in the light of the 4th industrial revolution: the regional association of vocational and technical education in Asia," Int. J. Train. Res., vol. 17, no. sup1, pp. 83-95, Jul. 2019, doi: 10.1080/14480220.2019.1629728.

[5] E. A. Hanushek, L. Woessmann, and L. Zhang, "General Education, Vocational Education, and LaborMarket Outcomes over the Life-Cycle,” No. 17504, 2011, doi: 10.3368/jhr.52.1.0415-7074R

[6] T. Agrawal, "Vocational education and training programs (VET): An Asian perspective," Asia-Pacific J. Coop. Educ., 2013, Available at: Google Scholar

[7] B. Panth and R. B. Caoli-Rodriguez, Competence-based Training in South Asia, 2017, Competence., vol. 23, doi: 10.1007/978-3-319-41713-4.

[8] S. Mehrotra, "Technical and Vocational Education in Asia: What can South Asia Learn from East/South East Asia?," Indian J. Labour Econ., vol. 59, no. 4, pp. 529-552, Dec. 2016, doi: 10.1007/s41027-017-0079y.

[9] A. Meiriza, E. Lestari, P. Putra, A. Monaputri, and D. A. Lestari, "Prediction Graduate Student Use Naive Bayes Classifier," in Proceedings of the Sriwijaya International Conference on Information Technology and Its Applications (SICONIAN), 2020, vol. 172, pp. 370-375, doi: 10.2991/aisr.k.200424.056.

[10] J. C. Alejandrino, A. J. P. Delima, and R. N. Vilchez, "IT Students Selection and Admission Analysis Using Naïve Bayes and C4.5 Algorithm," Int. J. Adv. Trends Comput. Sci. Eng., vol. 9, no. 1, pp. 759-765, 2020, doi: 10.30534/ijatcse/2020/108912020.

[11] C. Márquez-Vera, C. Romero Morales, and S. Ventura Soto, "Predicting school failure and dropout by using data mining techniques," Rev. Iberoam. Tecnol. del Aprendiz., vol. 8, no. 1, pp. 7-14, 2019, doi: 


\subsection{9/RITA.2013.2244695.}

[12] O. M. Musau, K. Omieno, and R. Angulu, “Towards Prediction of Students' Academic Performance in Secondary School Using Decision Trees,” Int. J. Res. Innov. Appl. Sci., vol. IV, no. X, pp. 85-89, 2019, Available at: Google Scholar.

[13] T. Pattiasina and D. Rosiyadi, "Comparison of Data Mining Classification Algorithm for Predicting The Performance of High School Students,” J. Techno Nusa Mandiri, vol. 17, no. 1, pp. 22-30, Mar. 2020, doi: 10.33480/techno.v17i1.1226.

[14] B. Khan, M. Sikandar Hayat Khiyal, and M. Daud Khattak, "Final Grade Prediction of Secondary School Student using Decision Tree," Int. J. Comput. Appl., vol. 115, no. 21, pp. 32-36, 2019, doi: 10.5120/202782712.

[15] I. Oliveira, "Classifying: Comprehension Of Students And Teachers Of Primary School," nternational Congr. Math. Educ., no. January 2019, 2019, Available at: Google Scholar

[16] M. Singh, H. Nagar, and A. Sant, "Using Data Mining to Predict Primary School Student Performance," IJARIIE, vol. 2, no. 1, pp. 43-46, 2019, Available at: Google Scholar

[17] B. Fauth, J. Decristan, S. Rieser, E. Klieme, and G. Büttner, "Student ratings of teaching quality in primary school: Dimensions and prediction of student outcomes," Learn. Instr., vol. 29, pp. 1-9, 2019, doi: 10.1016/j.learninstruc.2013.07.001.

[18] G. Supriyanto, I. Widiaty, A. G. Abdullah, and Y. R. Yustiana, "Application expert system career guidance for students," J. Phys. Conf. Ser., vol. 1402, no. 6, p. 066031, Dec. 2019, doi: 10.1088/17426596/1402/6/066031.

[19] A. Yağci and M. Çevik, "Prediction of academic achievements of vocational and technical high school (VTS) students in science courses through artificial neural networks (comparison of Turkey and Malaysia)," Educ. Inf. Technol., vol. 24, no. 5, pp. 2741-2761, Sep. 2019, doi: 10.1007/s10639-019-09885-4.

[20] A. Sucipto and J. Minardi, "Neural Network Model for Mathematic Scores Prediction: Case Study in SMK Negeri Pakis Aji, Jepara, Indonesia,” EKSAKTA J. Ilmu-ilmu MIPA, vol. 20, no. 1, pp. 28-35, Jan. 2020, doi: 10.20885/EKSAKTA.vol1.iss1.art5.

[21] I. G. P. Christyaditama, I. M. Candiasa, and I. G. A. Gunadi, "Optimization of artificial neural networks to improve accuracy of vocational competence selection of vocational school students using nguyen-widrow," J. Phys. Conf. Ser., vol. 1516, no. 1, p. 012052, Apr. 2020, doi: 10.1088/1742-6596/1516/1/012052.

[22] A. Yağcı and M. Çevik, "Predictions of academic achievements of vocational and technical high school students with artificial neural networks in science courses (physics, chemistry and biology) in Turkey and measures to be taken for their failures," SHS Web Conf., vol. 37, p. 01057, Aug. 2017, doi: 10.1051/shsconf/20173701057.

[23] B. Kitchenham and S. Charters, "Guidelines for performing Systematic Literature Reviews in Software Engineering; Technical report EBSE-2007-01; EBSE: UK, Durham,” 2007, Available at: Google Scholar

[24] D. Denyer and D. Tranfield, "Producing a systematic review.," in The Sage bandbook of organizational research methods., Thousand Oaks, CA: Sage Publications Ltd, 2009, pp. 671-689, Available at: Google Scholar

[25] E. El Haji, A. Azmani, and M. El Harzli, "Expert system design for educational and vocational guidance, using a multi-agent system," in 2014 International Conference on Multimedia Computing and Systems (ICMCS), 2014, pp. 1018-1024, doi: 10.1109/ICMCS.2014.6911256.

[26] A. Çetinkaya and Ö. K. Baykan, "Prediction of middle school students' programming talent using artificial neural networks," Eng. Sci. Technol. an Int. J., no. xxxx, Aug. 2020, doi: 10.1016/j.jestch.2020.07.005.

[27] A. A. J. Permana, L. J. E. Dewi, and K. Setemen, "Recommendation System for Selection of Majors and Apprenticeship on Vocational and Training Education Based on Competency to Produce Demand Driven Graduates," in Proceedings of the 2nd International Conference on Innovative Research Across Disciplines (ICIRAD 2017), 2017, no. January, doi: 10.2991/icirad-17.2017.29.

[28] U. B. Özkan, H. Cigdem, and T. Erdogan, "Artificial Neural Network Approach to Predict LMS Acceptance of Vocational School Students," Turkish Online J. Distance Educ., vol. 21, no. 3, pp. 156-169, Jul. 2020, doi: 10.17718/tojde.762045. 
[29] R. Damiaza and D. Fitrianah, "Prediction Analysis of Kartu Jakarta Pintar (KJP) Awardees in Vocational High School XYZ Using C4.5 Algorithm," Int. J. Mach. Learn. Comput., vol. 10, no. 1, pp. 44-50, Jan. 2020, doi: 10.18178/ijmlc.2020.10.1.896.

[30] R. Marlina, Adrianto, W. Amaldi, and M. J. Budiman, "Optimization of Algorithm C4.5, Naive Bayes With Particle Swarm Optimization in Predicting Career Suitability of Vocational High School Students: Case Study of SMKN 1 Rangkasbitung," Int. J. Comput. Tech., vol. 5, no. 5, pp. 146-153, 2018, doi: 10.13140/RG.2.2.26994.45764.

[31] F. Nasution and E. Muiza Zamzami, "Prediction of Vocational Students Behaviour using The k-Nearest Neighbor Algorithm,” J. Phys. Conf. Ser., vol. 1566, no. 1, p. 012046, Jun. 2020, doi: 10.1088/17426596/1566/1/012046.

[32] V. Aarkog, B. Wahlgren, C. H. Larsen, K. M. Andrson, and S. Gottlieb, "Decision-Making Processes Among Potential Dropouts in Vocational Education and Training and Adult Learning," Int. J. Res. Vocat. Educ. Train., vol. 5, no. 2, 2018, doi: 10.13152/IJRVET.5.2.2.

[33] R. Harimurti, Y. Yamasari, Ekohariadi, Munoto, and B. I. G. P. Asto, "Predicting student's psychomotor domain on the vocational senior high school using linear regression," in 2018 International Conference on Information and Communications Technology (ICOIACT), 2018, vol. 2018-Janua, pp. 448-453, doi: 10.1109/ICOIACT.2018.8350768.

[34] J. Diedrich, A. C. Neubauer, and A. Ortner, "The Prediction of Professional Success in Apprenticeship: The Role of Cognitive and Non-Cognitive Abilities, of Interests and Personality," Int. J. Res. Vocat. Educ. Train., vol. 5, no. 2, pp. 82-110, Aug. 2018, doi: 10.13152/IJRVET.5.2.1.

[35] J. Zhang, J. T. Du, and F. Xu, "Application of Data Mining in MOOCs for Developing Vocational Education: A Review and Future Research Directions," Int. J. Inf. Educ. Technol., vol. 8, no. 6, pp. 411417, 2018, doi: 10.18178/ijiet.2018.8.6.1073.

[36] L. Lannegrand-Willems, O. Cosnefroy, and A. Lecigne, "Prediction of various degrees of vocational secondary school absenteeism: Importance of the organization of the educational system," Sch. Psychol. Int., vol. 33, no. 3, pp. 294-307, Jun. 2012, doi: 10.1177/0143034311418912.

[37] C. Verma, A. S. Tarawneh, Z. Illes, V. Stoffova, and M. Singh, "National Identity Predictive Models for the Real Time Prediction of European School's Students: Preliminary Results," in 2019 International Conference on Automation, Computational and Technology Management (ICACTM), 2019, pp. 418-423, doi: 10.1109/ICACTM.2019.8776842.

[38] R. Agustina, Y. S. Dwanoko, G. Susanto, W. Kuswinardi, H. L. Purwanto, and D. Suprianto, "Decision making system vocational high school election using promethee method," J. Phys. Conf. Ser., vol. 1375, no. 1, p. 012039, Nov. 2019, doi: 10.1088/1742-6596/1375/1/012039.

[39] R. J. Salaki, C. R. Kawet, R. Manoppo, and F. Tumimomor, "Decision Support Systems Major Selection Vocational High School in Using Fuzzy Logic Android-Based," Int. Conf. Electr. Eng. Informatics, Its Educ. 2015, no. October 2015, 2017, Available at: Google Scholar

[40] J. N. Purwaningsih and Y. Suwarno, "Predicting students achievement based on motivation in vocational school using data mining approach," in 2016 th International Conference on Information and Communication Tecbnology (ICoICT), 2016, vol. 4, no. c, pp. 1-5, doi: 10.1109/ICoICT.2016.7571880.

[41] H. I. Bulbul and O. Unsal, "Determination of Vocational Fields with Machine Learning Algorithm," in 2010 Ninth International Conference on Macbine Learning and Applications, 2010, no. December 2010, pp. 710-713, doi: 10.1109/ICMLA.2010.109.

[42] D. M. Khairina, F. Ramadhani, S. Maharani, and H. R. Hatta, "Department recommendations for prospective students Vocational High School of information technology with Naïve Bayes method," in 2015 2nd International Conference on Information Technology, Computer, and Electrical Engineering (ICITACEE), 2015, pp. 92-96, doi: 10.1109/ICITACEE.2015.7437777.

[43] L. Melian and A. Nursikuwagus, "Prediction Student Eligibility in Vocation School with Naïve-Byes Decision Algorithm," IOP Conf. Ser. Mater. Sci. Eng., vol. 407, no. 1, p. 012140, Sep. 2018, doi: 10.1088/1757-899X/407/1/012140.

[44] N. L. Cintya Dewi, A. Prasteya Wibawa, and U. Pujianto, “Technology Acceptance Model on Internship 
Placement Recommendation System Based on Naïve Bayes," in 2018 International Conference on Sustainable Information Engineering and Technology (SIET), 2018, pp. 151-155, doi: 10.1109/SIET.2018.8693199.

[45] A. D. Herlambang, S. H. Wijoyo, and A. Rachmadi, "Intelligent Computing System to Predict Vocational High School Student Learning Achievement Using Naïve Bayes Algorithm,” J. Inf. Technol. Comput. Sci., vol. 4, no. 1, p. 15, Jun. 2019, doi: 10.25126/jitecs.20194169.

[46] W. K. Dewanto, K. Agustianto, and B. E. Sari, "Developing thinking skill system for modelling creative thinking and critical thinking of vocational high school student," J. Phys. Conf. Ser., vol. 953, no. 1, p. 012115, Jan. 2018, doi: 10.1088/1742-6596/953/1/012115.

[47] S. Wongpun and A. Srivihok, "Comparison of attribute selection techniques and algorithms in classifying bad behaviors of vocational education students," in 2008 2nd IEEE International Conference on Digital Ecosystems and Technologies, 2008, pp. 526-531, doi: 10.1109/DEST.2008.4635213.

[48] T.-T. Tran, "Forecasting strategies and analyzing the numbers of incoming students: Case in Taiwanese vocational schools," Int. J. Adv. Appl. Sci., vol. 4, no. 9, pp. 86-95, Sep. 2017, doi: 10.21833/ijaas.2017.09.011.

[49] O. Deperlioglu and F. S. Birtil, “Analysis of Girls Vocational High School Students' Academic Failure Causes with Data Mining Techniques," Anthropol., vol. 23, no. 3, pp. 505-512, Mar. 2016, doi: 10.1080/09720073.2014.11891970.

[50] S. Abadi et al., "Application model of k-means clustering: insights into promotion strategy of vocational high school," Int. J. Eng. Technol., vol. 7, no. 2.27, p. 182, Aug. 2018, doi: 10.14419/ijet.v7i2.11491.

[51] R. J. Salaki, C. R. Kawet, R. Manoppo, and F. Tumimomor, "Decision Support Systems Major Selection Vocational High School in Using Fuzzy Logic Android-Based," Int. Conf. Electr. Eng. Informatics, Its Educ. 2015, no. October 2015, 2015, Available at: Google Scholar

[52] M. Pilz, J. Li, R. Canning, and S. Minty, "Modularisation approaches in Initial Vocational Education: evidence for policy convergence in Europe?," J. Vocat. Educ. Train., vol. 70, no. 1, pp. 1-26, Jan. 2018, doi: 10.1080/13636820.2017.1392994.

[53] J. B. G. Tilak, "Vocational Education and Training in Asia," 2018, pp. 203-220, doi: 10.1007/978-981-130250-3_5.

[54] H. Sakai and M. Nakata, "Rough set-based rule generation and Apriori-based rule generation from table data sets: a survey and a combination,” CAAI Trans. Intell. Technol., vol. 4, no. 4, pp. 203-213, Dec. 2019, doi: 10.1049/trit.2019.0001.

[55] D. Hartama, A. Perdana Windarto, and A. Wanto, "The Application of Data Mining in Determining Patterns of Interest of High School Graduates,” J. Phys. Conf. Ser., vol. 1339, p. 012042, Dec. 2019, doi: 10.1088/1742-6596/1339/1/012042. 